we recognised that we often had to balance competing demands, this did not mean that we were less skilled or had less to offer.

Our success shows that a support group can be sustained, despite demands on time. It succeeded for several reasons; through the Women's Therapy Centre we had access to the skills of a facilitator initially and at times of difficulty; our membership was relatively stable and highly motivated; finally, as women, we found it easier to accept the need for support.

Participation in a successful group made us reflect on support within psychiatry. Although individual psychiatrists receive support from various sources, there is no generally recognised support system. This is worrying since our working lives are largely spent caring for others, and dealing with profound distress. At times the profession seems to imply that only the weak or inexperienced need support. Perhaps this stems from understandable fears of appearing needy, which the seductive image of the omniscient medical scientist so emphasised in training does little to dispel. Such attitudes, however, diminish staff and patients alike.

\section{Further reading}

EQUAL OPPORTUNITIES COMMISSION (1982) Caring for the Elderly and Handicapped: Community Care Policies and Women's Lives.

Kaufman Cartwright, L. (1987) Occupation stress in women physicians. In Stress in Health Professionals (eds R. Payne and J. Firth-Cozens). Chichester: John Wiley.

KRzowsKI, S. \& LAND, P. (1988) (eds) In Our Experience: Running Workshops with Women. London: Women's Press.

MARgison, F. R. (1987) Stress in Psychiatrists (eds R. Payne and J. Firth-Cozens). Stress in Health Professionals. Chichester: John Wiley.

SCARR, S. \& DUNN, J. (1987) Mothercare/Othercare. Harmondsworth: Penguin.

\title{
Meetings for the relatives of refugees from Vietnam suffering from schizophrenia
}

\author{
M. J. BlaCkwell, Senior Registrar in Psychiatry, St Thomas' Hospital, London SE1; \\ formerly Research Registrar, Department of Psychiatry, UMDS, Guy's Hospital \\ (Correspondence to Department of Psychiatry, UMDS, Guy's Hospital, \\ London SE1 9RT)
}

The problems of diagnosis in transcultural psychiatry and the ideological and anthropological questions raised have received much attention in the psychiatric literature over the last 15 years. Even when the diagnosis is not in dispute, specific problems are encountered in the delivery of psychiatric care to patients from ethnic minorities (Littlewood \& Lipsedge, 1989; Rack, 1982). Different explanatory models of illness and treatment, linguistic and cultural misunderstandings and numerous, apparently minor, practical difficulties bedevil treatment. Contributions to the psychiatric literature of practical use in management and service designs have been sparse.
In 1985 evidence given to the Home Affairs Committee of the House of Commons indicated an "alarming incidence" of psychological problems among refugees from Vietnam (this was not quantified however). It was suggested by the committee that a special service be set up. Our service and the meetings they have produced have been an attempt to meet this need.

\section{The problems}

In London, it is estimated that there are 12,000 refugees from Vietnam (British Refugee Council, 1987). The cultural and linguistic diversity of 
refugees from Vietnam, in itself, presents difficulties for the Western psychiatrist. Among refugees from Vietnam there are two main languages spoken; $80 \%$ of the refugees are Chinese and, while most speak Vietnamese and Cantonese, there are significant minorities who only speak one of these languages. In addition to linguistic and ethnic divisions, the community is further subdivided in a number of ways, all of which may affect the course of management. The labels "Communist", "Capitalist", "Buddhist", "Catholic", "Northerner" and "Southerner" reflect only some of the many variations of cultural, religious and political backgrounds among the refugees. Many are illiterate and unable to read maps. Even appointment cards and maps in the client's own language are often insufficient to ensure the person's attendance.

Eighty per cent of refugees from Vietnam were found to be unemployed in 1985 (Home Affairs Committee of the House of Commons, 1985). The resulting economic stringency has been exacerbated by several of our clients not signing on due to their illness. Furthermore, not being part of the National Health Service, the fares of patients or relatives who come and see us could not be paid.

Although there are some clusters of families from Vietnam in what tend to be the poorer parts of inner city boroughs they are, on the whole, widely dispersed. In the London area we are aware of only one general practitioner from Vietnam and two qualified Vietnamese social workers. There are no psychologists, occupational therapists or psychiatric nurses. Centralised activity is therefore highly desirable.

British social institutions, in particular the law relating to mental health but also the less obvious values and assumptions implicit in attitudes to mental illness, can be a major source of misunderstanding and even conflict.

A 20-year-old man who was suffering from schizophrenia had been threatening to kill his sister and was keeping a knife under his bed. I went to the house, where a number of members of the family had assembled, and attempted to persuade him to have an injection of a depot neuroleptic. The family tried to persuade me to give the injection while they held the young man down. My explanation of the law as applied to this situation was greeted with incredulity. It was simply not possible to convey the legal, moral and ideological underpinnings of our system which meant that the young man would have to be seen by a social worker and another doctor whose agreement would be necessary before he be taken to hospital and given the injection.

Cultural attitudes and beliefs constantly present the health worker with challenges. The notion of an enormous wealth of shared knowledge and expertise allowing doctors to identify syndromes, prognosticate and treat correctly is alien. Some Chinese doctors learn all they know from their own family, and by experience, and some have secret family remedies. One's personal credibility as a doctor, therefore, derives solely from how the patient is doing. A patient with a chronic and relapsing condition who deteriorates despite treatment (which itself causes serious side effects), leads to loss of confidence in the Western psychiatrist.

Different explanatory models of illness, prognosis and treatment, held by doctors and patients, arising within their diverse conceptual frameworks, are a particular problem. If the doctor and patient or relative cannot agree what, if anything, is wrong, management can hardly be agreed. The refugees' explanatory models of schizophrenia have included possession, dietary indiscretion (where too much "hot air" in the body leads to irritability), laziness and a broken heart. Exorcism, dietary change and arranged marriages are healing manoeuvres which have been attempted. A number of our clients have been beaten for apparent indolence when displaying negative symptoms of schizophrenia.

A 15-year-old school boy gradually developed a schizophrenic illness culminating in his taking captive his deputy headmistress in an office and holding her by the throat for an hour. For the previous six months he had had difficulty in sleeping and his school work had been suffering. He was also reported as having had an episode of talking nonsense at the beginning of that period. The response of his family to these prodromal symptoms was that both his father and elder brother were very angry and had, on occasions, given him a slap.

Chinese and Vietnamese people tend to be pragmatic in their approach to illness. Simple ethnomedical procedures, e.g. dietary change, are tried first and then perhaps acupuncture, Chinese herbs or exorcism. Western doctors may then be tried but are often given a limited period to succeed before other avenues are explored. All these approaches may be going on at once. In general, Western medicines are seen as powerful (but frequently prescribed in excessive doses for Chinese and Vietnamese) and having very dangerous side effects. It is often considered prudent, therefore, to take Western medicines in a lower dose and for a shorter period than is prescribed.

This style of seeking and accepting health care is particularly ineffective for a condition which is chronic and slowly responsive to treatment which itself may cause dramatic side effects. The need for long-term therapy, (which often only ameliorates symptoms), the occurrence of acute relapses despite treatment and the lack of outward signs of "real illness" have obvious consequences when viewed from the cultural perspective outlined above. The pragmatism of people from Vietnam and the chronicity of schizophrenia combine eventually to ensure effective treatment. However, in the meantime treatment of a devastating and occasionally fatal illness is delayed, inadequate, prematurely interrupted or simply not given at all. 
A 16-year-old school boy was admitted to hospital after leaping from his family's first floor flat and on arrival displayed many features of catatonic schizophrenia. He was given neuroleptic medication and two days later the family brought a Buddhist priest to him who performed an exorcism ceremony. At about this time he recovered and went home. The family were convinced the exorcism had cured him and medication was stopped. He quickly relapsed and had to be re-admitted after becoming floridly psychotic and assaulting his grandmother.

His grandfather, now convinced of the value of medication, and having sufficient personal authority, instructed his grandson to continue taking his medication. He remained well for several months.

As in Western society, the stigma attaching to mental illness is important. The negative effects of stigma include not seeking help, denial, extrusion of the sufferer and rejection of the helpers. The admixture of Confucian values with the beliefs of Buddhism and the cult of ancestor worship is a potent amplifier of stigma. The Confucian's idea of self-worth is dependent on the honour or shame he brings on his family. The Buddhist may see misfortune as punishment for evil doings. The cult of ancestor worship not only dictates that any wrongdoing in this life shames one's ancestors but also that any punishment due to one's ancestors may be visited upon living relatives. Therefore the patient, either now or in a former life, or his living relatives or his ancestors may be seen as responsible for the misfortune and as undoubtedly having committed some evil act to bring it about. Mental illness shames the family and admitting to it or demonstrating it publicly further disgraces them. All family members are "devalued" by such occurrences. No-one admits to the problem so each family feels alone. The cultural association of mental illness with spirit possession adds to the stigma.

Parents of a moderately mentally handicapped woman of 23 , who also had schizophrenia, will not allow her to attend day centres partly because of the stigma involved. The mother believes that her frame of mind during pregnancy caused her daughter's disability. At that time her mother-in-law was extremely cruel to her, she became very depressed and willed her baby to die. Her daughter's appearance at a centre will only increase the shame her mother has already brought on the family by publicly displaying it.

\section{The project}

The United Medical and Dental Schools Psychiatry Liaison Project for the Vietnamese Community in London has at the time of writing been in existence for $\mathbf{2 0}$ months. In the absence of Vietnamese professionals it was proposed that two people, themselves refugees, would be employed on a half-time basis with a full-time psychiatrist. While providing a psychiatric service to the community the two workers would be trained as mental health workers, who, at the end of the project, would be capable of providing a useful service to the refugees from Vietnam in a largely independent fashion. The training was to be largely in-service. Fortunately, the workers subsequently employed between them possessed many of the characteristics of the diverse community mentioned above. They were a Chinese man from the North and a Vietnamese woman from the South.

The aims of the project have been:

(a) to provide a liaison service between psychiatric services and the Vietnamese people in London

(b) to provide a counselling service to refugees from Vietnam in London

(c) to provide an educational service to refugees and refugee workers to enable them to use psychiatric services and other appropriate services effectively

(d) to provide an educational service about Vietnamese culture and attitudes to mental health for all personnel working with distressed people from Vietnam

(e) to provide training and experience to refugee workers from Vietnam to enable them to fulfil the roles mentioned above.

The project had had an open referral system with almost all consultations taking place in the clients' homes.

The project has received 85 referrals to date and, of these, forty-one have fulfilled the DSM-III criteria for a diagnosis of schizophrenia. In the management of this particular illness we have been at pains to involve local services, whether through the GP or by direct approach to the catchment area psychiatrist. It has not been the purpose of the project to form a service separate from the mainstream of psychiatry but rather to aid our clients in the use of statutory services.

During the course of the project the two workers have not been single-handed in providing a cultural consultancy. There has been an advisory committee of refugees from Vietnam who have been consulted about the management of a number of our clients.

\section{The meetings}

It quickly became clear during the course of the project that, despite our combined linguistic and cultural skills and professional training, certain problems still seemed insuperable. Difficulties relating to stigma, conflicting explanatory models of illness and treatment, professional credibility, patient mobility and isolation were often not remediable by our interventions alone. Combined meetings to tackle these problems and to reduce critical expressed emotion in the relatives seemed a rational approach (Leff $e t$ al, 1985). 
The meetings have been held in a basement in London's Chinatown close to one of the cheapest and most popular supermarkets. The entrance is between a sex cinema and a Catholic Church. The location has the triple advantage of being completely anonymous, easy to find as most people know the supermarket in question and it is apparently neutral in political and religious terms. The relatives were given maps in Vietnamese and Chinese but were also told simply to wait outside the supermarket. Invitations stressed the confidentiality and anonymity of the meetings. A grant had been obtained from a charitable trust which allowed us to offer to pay the fares to and from the meetings for the relatives.

The meetings were conducted largely by the mental health workers and opened with a talk given about schizophrenia in both Vietnamese and Cantonese by the two workers. This talk has a number of functions. It attacks stigma by stressing the evidence for a physical aetiology, refuting the notion of immorality in the families of schizophrenics and emphasising the universality of the illness and its frequency. One phrase used is, "Western doctors see as much shame in this illness as in a broken leg". In addition to the reasoned argument against the stigma attaching to mental illness the talks also contain personal statements from the project workers who, far from disparaging the relatives, stress their respect for the way they have looked after their sick family member.

The talk also seeks to decrease critical expressed emotion by presenting the evidence for critical face-to-face contact increasing the breakdown rate followed by suggestions for alternative behaviour. It is pointed out that changes in behaviour of the sick family member are most likely to be due to the illness rather than "naughtiness" or "laziness".

The talk continues with a description of the phenomena seen in schizophrenia and the effect that medication is likely to have on its course. It also contains an explanation of the rationale for using medication which might have serious and unpleasant side effects.

A short break follows when Chinese tea and buns are distributed and then there is a question-andanswer session for 30-60 minutes. Each question is translated into the other language and the answer, although given by the author, is translated into both languages. A considerable period is left at the end of the meeting for refreshments and an opportunity to socialise. In the question-and-answer session the various explanatory models of schizophrenia mentioned above are often referred to. We are at pains not to directly contradict these except where they are themselves stigmatising or likely to harm to patient, e.g. "He is lazy so I hit him". A typical formula we would adopt, using cultural idioms with meanings for the refugees, would be: "I cannot say whether 'Quynh's' illness is supernatural in origin. What I do know is that he has schizophrenia, in which there is an imbalance in the body similar to an imbalance of Ying and Yang. This illness will probably only improve with medicines which redress the imbalance".

During the question-and-answer and informal socialising periods the opportunity is taken to discuss practical matters such as family reunion requests, housing transfers and social security benefit problems. An attempt is also made to explore and understand how conflicts arise due to differing values, assumptions and ideologies. No attempt is made to "convert" to our society's values, merely to increase understanding and look for solutions.

The older sister and eldest relative in this country of a 20 year-old schizophrenic man was asked to leave a case conference while a discussion between the professionals involved took place. She believed that, as the person taking responsibility for her brother, she should be involved in all discussions and was deeply hurt and complained bitterly about this occurrence. This compounded other difficulties arising from her demand for a firm diagnosis before it could be established. Once this had been made, members of the family were able to attend our meetings and some progress was made to resolving the difficulties.

The arranging of marriages for sick relatives is often discussed at the meetings. This is peculiarly sensitive as the family not only believe in the therapeutic effect of marriage but are also losing face by having an unmarried relative beyond the usual marrying age. The presence of other families who have gone down this path and share their experiences helps bring about a truly informed decision.

A 24 year-old schizophrenic woman who had progressed from being mute, bizarre and antisocial over two years to being socially appropriate, talkative and safe on depot neuroleptics for 18 months, had a marriage arranged. On hearing this we went to see her mother and grandparents with whom she lived. We pointed out that marriage would not cure her and held many disadvantages and difficulties for a schizophrenic woman requiring active treatment. The family went ahead with the marriage to a man with a mild mental handicap. She fell pregnant, medication was stopped and she relapsed. The child was lost. The couple have now separated. The family now attend our meetings and can share this knowledge.

More important than the practical and moral support offered by the workers mentioned above is that which is offered by the clients' relatives to each other. This is why considerable time is set aside for the refreshments and no one is encouraged to rush away after the meeting.

\section{Comment}

The meetings have undoubtedly gone some way to decreasing the stigma felt by the relatives. Their common sharing of experiences of schizophrenia in 
their family members has been one step removed from a living demonstration of the syndrome itself. It has clearly been a revelation to many of the relatives that, while the common features of schizophrenia are being described, other members of the group are nodding their heads in recognition. They have been overheard during the informal part of the meeting conferring with one another and confirming that they are presented with remarkably similar problems. Several have relayed to one another and to us, on subsequent visits to their houses, the evidence we actually presented at the meetings to counter stigma.

Unfortunately some of our clients' relatives have refused to come because of the very problems the meetings are designed to obviate. One husband of a schizophrenic woman used a Chinese expression equivalent to, "I don't want to wash my dirty linen in public" in refusing to attend.

When discussing critical expressed emotion, several of the relatives with longer experience have volunteered confirmation of our assertions from their own experience. A number of families have reported that they have become more accepting and encouraging since attending the meetings. Relatives of the 15 year-old schoolboy mentioned earlier heeded our advice, and following a short course of neuroleptics he was able to return to school and was well when seen several months later.

The aim of supporting the relatives has been successfully fulfilled. The simple fact of meeting other refugees from Vietnam with the same problem is clearly greatly valued as the relatives have now decided to run their own informal association. The stigma felt within the community had prevented the relatives from seeking support from those who could best understand. Several friendships have started up between families. The sheer numbers of people at the meetings has, in itself, been helpful. The opportunity to share experiences and discuss common problems has been unique and has produced a sense of solidarity.

In several instances the explanatory models and consequent interventions rooted in Vietnamese culture which would not have been helpful have been mentioned and members of other families have been able to share their experience of these. The inappropriateness of the explanatory model or the inefficacy of the resultant intervention have been pointed out by other refugees.
We believe that some of the specific problems in providing a service to this community could only have been tackled in this way. The problems of reaching a widely dispersed client group whose mobility is compromised for a variety of reasons necessitates this kind of meeting. The problems of credibility mentioned above where the scientific knowledge base of the Western doctor is neither known nor understood are probably unsurmountable without this kind of concrete verification.

There have now been seven meetings. A total of 27 relatives representing 18 families have attended. Nine families did not accept our invitation; $76 \%$ of available families were represented. We have the impression that the meetings have been effective in achieving the four stated aims. Our experience prior to the meetings was that such results simply could not have been achieved by ordinary discussion between the project team and the clients and their families.

\section{Acknowledgements}

I would like to thank the Mental Health Foundation and King's Fund for their financial support of the project as a whole and the Airey Neave Trust for a special grant in support of these meetings. I would also like to thank the parish of The French Catholic Church, Leicester Square who generously allowed the use of their hall free of charge because of the nature of the function.

\section{References}

BRITISH RefugeE CoUnCIL (1987) Unpublished internal report. See German, G. A. (1987) Mental Health in Africa. The British Journal of Psychiatry, 151, 435-439.

LeFF, J., KuIPERS, L., Berkowitz, R. \& STURGeon, D. (1985) A controlled trial of social intervention in the families of schizophrenic patients: two year follow up. The British Journal of Psychiatry, 146, 594-600.

LitTlewOOD, R. \& LIPSEDGE, M. (1989) Aliens and Alienists. Second edition. London: Unwin-Hyman.

RACK, P. (1982) Race Culture and Mental Disorder. London: Tavistock Publications.

REPORT OF HOME AFFaIRS COMMTTTE OF THE HOUSE OF Commons (1985) Third Report on Refugee Asylyum. London: HMSO. 